\title{
ONE DAY AT A TIME: THE POLITICAL LIMITS OF THE DOMESTIC SITCOM
}

\author{
André Carvalho ${ }^{1}$ \\ Marília Dantas Tenório Leite ${ }^{1^{* *}}$ \\ Paola da Cunha Nichele $e^{1 * * *}$ \\ ${ }^{1}$ Universidade Federal de Santa Catarina, Florianópolis, SC, Brasil
}

\begin{abstract}
Most critics argue that the television comedy One Day at a Time (2017), produced in the United States, is a progressive show, mainly due to its cast, its attempt at faithfully representing an ethnic minority, and its courage in advancing relevant, sensitive topics. In order to qualify such assumptions, we will review the history of the sitcom formula, particularly the genre often defined as domestic comedies of the 1970s, and argue that its formal constraints impose unsurmountable limits on a progressive agenda. Finally, we proceed with an aesthetic analysis of the first season, which further demonstrates that the genre's need of family stability-what we call a hierarchy of values-compromises the dramatization of political content. We hope that by examining the genre's history and analyzing the show's aesthetic, we can contribute to a better understanding of its inherent shortcomings and compromises.

Keywords: television; sitcom; domestic comedy; One Day at a Time; political critique
\end{abstract}

\footnotetext{
"Holds a PhD in Language and Literature (UNESP-Rio Preto). He is currently a postdoctoral fellow at the English Graduate Program (PPGI) at Federal University of Santa Catarina (UFSC). E-mail: carvalhoandre@ outlook.com. Orcid: https://orcid.org/0000-0001-9172-3498.

" Has an MA in Translation Studies (UFSC) and is currently a PhD candidate in English Literature at Federal University of Santa Catarina (UFSC/CAPES). E-mail: marilia_@live.com. ORCID: https://orcid.org/00000002-3177-5031.

${ }^{* * *}$ Has an MA in Literary and Linguistic Studies in English (UFSC) and is currently a PhD candidate in English Literature at Federal University of Santa Catarina (UFSC/CAPES. E-mail: paolanichele3@gmail.com. ORCID: https://orcid.org/0000-0002-8408-8104.
} 


\section{Introduction}

One Day at a Time (2017) is a remake of Norman Lear's successful production of the same name, which ran on CBS from 1975 to 1984 . The original series portrayed Ann Romano, a divorced woman raising her two daughters by herself, which was enough of a controversy for television in the 1970s. The remake's showrunners, Gloria Calderón Kellet and Mike Royce, completely revamped the show, turning Ann into Penelope Alvarez, a Latina Army veteran suffering from post-traumatic stress disorder (PTSD), who is also raising her children after a separation. The older daughter, Elena, is a feminist and an activist in the process of discovering her sexual orientation. Alex, the prepubescent son, is the typical comic relief, often the butt of jokes and gags. He is pampered by Lydia Riera, Penelope's mother, a Cuban refugee who came to the U. S. as a young adult during Operation Peter Pan, soon after the Cuban Revolution took place. Lydia is by far the most festive character on the show, a self-conscious portrayal of Latino stereotypes, which include a fervent Catholicism and rumba moves.

In the next few pages, we will argue that One Day at a Time has been welcomed by critics as a progressive show in television, mainly due to its cast, its attempt at faithfully representing an ethnic minority, and its courage in advancing relevant, sensitive topics. Although we agree with most of the reviews, this paper will also question how well can such a content be articulated within the conventions of the sitcom. This will take us to a discussion around the transformations of the sitcom formula, particularly the genre often defined as domestic comedies of the 1970s (Newcomb, 1974) and their socially relevant (Gitlin, 1983) instances, exemplified by the original shows of Norman Lear and their derivations. How did the wish for a political debate between conservatives and progressives in television-the "cultural forum ideal" (Newcomb \& Hirsch, 1983)-take form within the conventions of the domestic comedy? What compromises were already evident in the 1970s between the format's need for episodic closure and the development of complicated controversies dramatized in serialized character evolution (Feuer, 1984)? And, most importantly, how are these issues still present in popular television fiction today? Following the historical considerations, we will proceed to an in-depth aesthetic analysis of a major plotline of One Day at a Time's first season. We will demonstrate how the formal constraints of the domestic sitcom impose limits on its progressive agenda, particularly by utilizing the device of an implied hierarchy of values, which informs the character's actions. In sum, while not denying that this and similar types of shows deserve the credit for their multi-ethnical production team and cast, as well as for refusing to reproduce negative stereotypes, we claim that, by examining the genre's history and by taking a closer look at show's content, we can contribute to a better understanding of its shortcomings. 


\section{A progressive show}

In most critical reviews, the acclaim of One Day at a Time is either taken for granted as a "success among critics" (Czajkowski, 2017) and public_-"audiences are loving it" (Kellet, 2017)—or supported by the "almost perfect score" on sites like Rotten Tomatoes, which aggregates professional and amateur opinions (Alvarez, 2019).

By examining these critiques more closely, we could observe they often employ three key elements: the cast, the representation of sexual and ethnic minority groups, and the foregrounding of sensitive/relevant topics. These are considered progressive achievements of the show, since they supposedly swim against the current of regular, hegemonic, television content. A fourth element present in almost all reviews has to do with authorship: the critics devoutly bow to Norman Lear, the legendary writer-producer of the 1970-80s who created the original show and was responsible for picking the showrunners of the remake, Gloria Calderón Kellet and Mike Royce. In this section, we will briefly comment on how each of the first three elements appear in critical reviews of the series and whether or not they stand scrutiny. In the next section, we will deal specifically with Norman Lear's influence and the history of the American sitcom as a genre.

\section{Cast}

This seems to be the least controversial point, therefore it is worth mentioning only in passing. Plenty of praise is given to the "impeccable chemistry" (Bradley, 2018) of the cast, especially to the show's leading role of Penelope, played by Justina Machado (Sepinwall, 2017). Often enough, throughout the reviews, actress Rita Moreno, in her role as Lydia, the 87-year-old matriarch, steals the spotlight: Alan Sepinwall claims she is a "legendary (...) comic miracle" who can turn "hammy and/or stereotypical" material into "hilarious moments that feel genuine." Margaret Lyons (2018), The New York Times main TV critic, echos this sentiment: "the brightest star in our solar system." Gloria Calderón Kellett, the show's co-creator, does not measure her words either: "Incredible. Goddess, icon" (Kellet \& Gomez, 2020).

Obviously, having a good ensemble in a sitcom is key, since so much depends on accurate comic timing. But the praise around Moreno's performance is more than just recognition for her craft and/or deference to Hollywood royalty, "an American treasure," according to Lili Loofbourow (2019): critics, actors and creators envy the joie de vivre of the octogenarian.

In a youth-centered media, with very little support for aging actors, it is refreshing to watch the veteran from West Side Story playing a "sexy, badass grandmother" (Stevenson, 2019), who rumba dances throughout the show and jokingly flirts with any attractive male that she encounters. However, a problem immediately comes to mind: she may move and dress "like she is 20 or 30 years younger" (Kellet \& Gomez), but her physical prowess does not extend as far as 
actually performing as a sexual being. She can be both the naughty grandma and the respectful and celibate widow, as long as the fire keeps alive only as a memory or as a playful tease.

This is a good initial example of how the show may seem progressive, but only up to a certain point: it is on the verge of tackling the taboo of elderly sexuality, but it does not go beyond innocent flirtation and recollections of the character's (monogamous, religious, within-a-marriage) sexual past. It invites us to gaze at her "abs" when she is wearing a crop top (Kellet \& Gomez), but perhaps this only help us forget our own fears about the aging body. It relieves the pressures and avoids the tensions of getting old by not going all the way into making Lydia a complete sexual being, with both the yearning lust and the possible frustrations that this would entail in a society that hardly recognizes a sexual dimension of the elderly.

\section{Representation}

Both reviewers and producers of the series use the word representation in its most commonplace definition. Having a show centered around a Cuban family, with almost all of the actors and half of the producers-writers being of Latino descent (Bradley) is considered an inherently beneficial factor. It pleases the Latino audience, who can see itself on the small screen, as well as it educates the broader public, who receives an overall positive image of Latino culture and customs in opposition to a previous tendency of representing Latino characters through negative and sometimes dehumanizing stereotypes. So, the show simultaneously boosts the self-esteem of a minority group and helps its "inclusion" by getting the non-Latino part of society better acquainted with the "cultural specificity" (Kang, 2017) of Latin American immigrants. After Netflix cancelled the show in 2019, it was frequent for fans and critics to mention that television lacks enough Latino comedies and dramas, so One Day at a Time should be kept on air to fill this demand (Piñero, 2019).

Calderón Kellet (Kellet \& Gomez) claims that her ethnic group is underrepresented in American television and, what is worse, that Latino characters are often "stereotypes ... gangbangers, drug dealers, and whatnot." Isabella Gomez (who portrays Elena Alvarez), in the same interview, adds: "I don't want to represent my community that way. I don't want to be a gangbanger girlfriend, or a drug addict, or any of that." One critic considers the series "one of the most resonating and personal TV shows for the Latinx community, breaking down limitations and misconceptions [...] with each thoughtprovoking episode" (Alvarez). The word "community" is omnipresent: "Latinx people and people of color tend to under-report and we like to talk about things that are important to the community" (Kellet \& Royce, 2020).

It is not our objective here to delve much deeper into the problems around the idea of Latino representation in the media (Stewart, 2019), ${ }^{1}$ but a few comments are needed, especially considering that there seems to be a widespread consensus over the meaning and the value of this idea. By discussing one specific show, we 
hope this can serve as a model to advance the subject, which is more and more relevant nowadays, as Netflix and other popular producers have been relying increasingly on the foregrounding of cultural difference.

All the quotes above seem to equate representation with the positive aspects of a community. Avoiding stereotypes, for both Calderón Kellet and Gomez, means avoiding the bad and emphasizing the good. Instead of criminal tendencies, a solid work ethic. Instead of the gang, the nuclear family. We cannot claim this is unreasonable: the percentage of "good people" in any particular ethnic group should obviously greatly outnumber the percentage of "bad people," and, for the sake of a naïve realism, it would be desirable to stick to these proportions when dealing with on-screen representation. However, the commonsensical "good vs. bad" dichotomy is the underlying assumption that remains unquestioned. It reinforces ideas of desirable vs. undesirable elements within a community, lawful vs. unlawful behavior, as if these were individual and moral choices instead of complicated, structural relationships taking place in numerous social constraints. Avoiding the issues of bad or unbecoming behavior in general is certainly a valid strategy for dissociating a whole community from these aspects of existence, but we argue that this choice may not leave room for the possibility of more complexity in the construction of characters and in the exploration of historical and social contexts. Choosing a middle-class setting with a strong network of familial support, which includes a mother, a grandmother and a generous landlord, certainly veers the representation of a community away from the world of crime, but it also relinquishes the opportunity to delve into the less photogenic aspects of the Latino experience, which are not only "bad," but consequences of history, public policies and economic conditions. Turning away from the stereotype of the "gangbanger girlfriend," for instance, might help dissociate this cliché from the Latino community, but it does little to prevent the vilification of actual people in that situation.

Here we may recall the classic paper from 1978 by Fiske and Hartley (11), in which they discussed content analysis, and demonstrated how it was already a trend in television to represent minorities in a positive rather than negative light. Relying on quantifiable data, they proved that while American society still appeared very racist and sexist, television writers and producers were compensating this fact by creating poor, women and black characters with disproportionate "good" traits in relation to rich, male and white counterparts. Fiske and Hartley's analysis does not go very deep, and we can see a limit to their methods of data quantification. For instance, it is questionable to simply compare the number of positive and negative traits in black and white characters alone, while disregarding the prominence of leading roles in relation to secondary roles. In the shows they analyzed, a disproportionate number of the villains were rich and white men, as if the creators would consciously refrain from casting underprivileged groups as villains. But their quantifiable data may not convey other subtle forms in which ethnic minorities are shoved out of the frame: is that really so relevant and progressive to have a black hero, if the white villain ends 
up getting more screen time and character development? What is still interesting about their research is how they verify the existence of a wish-fulfillment dynamic in popular fiction. Considering that One Day at a Time is contemporary to Donald Trump's derogatory remarks and extreme policies against Latino immigrants, the producers' work to reinforce a positive image of their community seems, above everything else, a (welcome) symptomatic response. However, considering the aesthetic possibilities, this approach may end up erasing valuable conflicts and contradictions from the screen, despite (actually, due to) the good intentions of writers and producers. Shows might lose the opportunity to develop complexity and moral ambiguity because they simply avoid framing the actions of ethnic minorities in that grey area.

There is also something that resembles the logic of advertisement here. Reinforcing the positive traits of a community is a clear attempt at inclusion and acceptance. The show, taking the responsibility of representing a whole community, does so by advertising it. This tendency to contain difference parallels the strategy to market a homogeneous and uncomplicated image of Latinos, which has been heavily deployed by advertisers and media executives since the 1970s, when Latinos emerged as a promising minority. According to D'Ávila's (2001) discussion on the commodification of Latino communities and the media's role in the construction of identities, the corporative drive that motivates a predilection for simplification produces a typified representation of communities-one that abuses clichés and stereotypes in order to render a people/market easier to digest, whether for potential clients or consumers (75).

The same previous observations apply: politically, this may seem like an obvious benefit for actual families wishing for cultural and political integration in a larger and unwelcoming society; aesthetically, it creates a constraint, an imperative to sweep under the mat problems which are too unpalatable for both the broad public and the community. Advertising a product is in direct contradiction to actually understanding its complexity, its social-historical manufacturing process and, to say the obvious, its shortcomings. In other words, it is the opposite of fully representing it.

We understand the impulse to avoid "bad" stereotypes of minorities, which abound in the media, as a counter-force. The previously quoted interviews make it clear that this choice is a direct response to their perception of a media that stigmatizes the Latino community, something that is corroborated by academic research (Castañeda, 2020; Mastro et al., 2008; Mastro \& Behm-Morawitz, 2016). However, we feel that this strategy might be further questioned and discussed in creative and critical circles: what is the compromise involved in depicting underprivileged communities and identities in the media in a positive and favorable light only (what we call "advertising" it), instead of using fiction to fully situate positive, negative (and grey) aspects, with all their problems and contradictions? And are these goals really mutually exclusive?

Ella Shohat and Robert Stam $(1994)^{2}$ argued this point thoroughly in their discussion about stereotypes in film. The authors recognize the importance of 
complex, nuanced representation, but question some of the assumptions behind the struggle for "empirically real" (accurate) portrayals and for "positive" (ideal) images (178, note 1) of minorities. They acknowledge the efforts Hollywood has been making towards "correcting" (189) generalizations about whole cultures and for casting actors that actually come from ethnic minorities being representedwhat they call the "stereotype approach" (199) - but they also realize the "theoreticalpolitical pitfalls" (199) of making these changes in the name of faithful representation (realism), thus forgetting that "narrative structure and cinematic strategies" might remain Eurocentric (190). The authors' approach, therefore, relieves the burden of representing a culture through positive or realistic images. They propose looking at all the discursive strategies employed in the work, something that goes beyond plot and character. In this brief discussion, we are also trying to avoid "the moralistic and essentialist traps embedded in a 'negativestereotypes' and 'positive-images' analysis" (215) present in the speech of the creators and in the response by the public. We believe they are still too much focused on "positive images", while disregarding the aesthetic and discursive framework of the domestic sitcom format. Just like Shohat and Stam argued, the formal conventions and discourses of the actual works may be in conflict with their authors' best intentions.

One critic calls One Day at a Time "the most revolutionary show on the network" (Stevenson), but considering the history of television we may understand that it follows a larger trend dating back from the 1970s. Since then, both the impact from the social movements of the 1960s and the ascension of a liberal, urban middle-class have been important factors for representing more diversity. The television industry was also beginning to work with segmented audiences, abandoning the idea of an undifferentiated viewing public. This increased the interest for greater diversity and also for political/polemical current issues, as we will see next.

The historical significance of the market segmentation of mass culture is widely documented, even before the rise of cable television and streaming services. Todd Gitlin, in the epilogue of his major work, uses the term narrowcasting (288), which will be adopted by several media scholars. Michael Curtin (1996) comments on the change from a Network Era to a Post-Network Era relating it to the transition from Fordism to Neofordism. He argues that even though we have more and more niches, the tendency to monopoly continues. In a more contemporary approach to this issue, Lotz (2014) discusses interesting creative opportunities during the rise of premium cable programming, especially in smaller cable channels. Finally, Jill Lepore's major recent account of the whole history of United States places a fundamental importance on market segmentation and the repeal of the Fairness Doctrine in 1987 by Ronald Reagan as precursors to the "epistemological abyss" (704) of political polarization, denial of science and fake news.

Our last decade is witnessing a similar movement. Netflix and other producers/providers, aided by new consumer research technologies, such as Big Data, can continue the tendency of targeting very specific niche audiences. This 
is clear in One Day at a Time, since it has been acknowledged that the main drive behind producing a sitcom about a Latinx family comes directly from a marketing survey, which found "single Latina mothers" as a "desirable demographics" (Fernandez, 2016; Kellet \& Gomez).

The lesson here is that regardless of the creator's and reviewers' best intentions, equality on screen is made possible only when financial equality is on the horizon. The target audience may find itself represented in a positive light when at least two conditions are met: they have individual artists like Gloria Calderón Kellet, who has been able to attain professional excellency; and when their specific community is found to be a good source of income, as consumers of advertising or subscriptions. ${ }^{3}$ Once again, diversity is perfectly compatible with the cultural industry when representation can be made into financial return. Far from "revolutionary," it is the very own basis of commercial entertainment.

Of course, the issue of Latinx representation cannot be properly and fully discussed in this subsection alone. In this article, we are emphasizing some of the blind spots that can hinder the creators' capacity to fully represent the complexity of Latinx experiences within a larger dynamic of formal aesthetic conventions and the media changing economy. Thus, we are qualifying views such as the ones present in Del Río \& Moran's paper (2019) ${ }^{4}$, which is exemplarily positive about One Day and a Time's power to overcome stereotypes in the landscape of Latinx television shows. The authors argue that the new model of subscription services, such as Netflix, allow for more detail and complexity which was not possible in the broadcast age, stating that "Sony and Netflix create the conditions for producer agency that valorizes national and cultural specificity within Latinidad" (17). In interviews with the creators, they again emphasize the creative freedom Netflix allowed them to produce a more specific and realistic portrayal of a Cuban family and consider the series to offer "a potential change of course for the general market representation of Latinidad" (2). It should be noted that their article was written before the cancellation of the show by Netflix. This fact alone already invalidates some of the arguments about the potential for radical change brought by the streaming model. In 2020, it is becoming increasingly clear that Netflix's investment strategies, which the authors claim "affords [the show] the luxury of operating outside the traditional economic system and genre conventions" (5) cannot sustain the production of series for niche audiences and so the differences from the broadcast age are blurred. Also, as we intend to demonstrate throughout this paper, it is arguable how much of One Day at a Time's aesthetic differs from the conventional sitcom model and how successfully it overcomes the good/bad dichotomy, as suggested by Del Río \& Moran’s article.

\section{Relevance}

The third and most important aspect of the critical reception of the show has to do with recognizing the openly controversial/contemporary themes it engages. Each author uses a different terminology for addressing this characteristic, such as 
"social commentary" (Fernandez), "contemporariness" (Kang), "socially conscious" (Kellet), "energetically political and progressive" (Lyons). These evaluations are based mainly on the sensitive subject matter dramatized in topical plots of each episode, as well as in long character arcs: military service and post-traumatic stress disorder, immigration and exile (Fernandez), therapy and the prejudices around seeking psychiatric help and medication, pornography and microaggressions in the workplace (Kang), gender equality, diversity and the struggles of "coming out" (Kellet), divorce, drug addiction and gun control (Lyons).

We shall adopt the umbrella term relevant, because it has a history on television studies, as in "The turn towards 'relevance," the title of a chapter in Todd Gitlin's classic, Inside Prime Time (1983). The term also encompasses the idea of controversial, polemic topics, depicted as the "hot" issues in the media.

It is clear that all critics realize the show's foregrounding of relevant issues. Our question is why this is flagged as a distinctive trait in a comedy. Margaret Lyons, after listing the controversial plot points, puts it bluntly: "This should probably be a gritty drama, or maybe a sour-smart single-camera auteurish dramedy. Instead it's the beautiful, improbable 'One Day at a Time', a multicamera family comedy." In other words, how could a "multicamera family comedy" deal with content more suited to a "gritty drama," or to an "auterish dramedy"?

Lyons comment reveals expectations for overtly polemical/political subject matter in prime-time TV drama, not comedy. How can a traditional threecamera sitcom, recorded in front of a live audience, move through the more difficult moments of tension? Can the puns, the gags and the physical comedy, punctuated by the omnipresent laugh track, cohabitate in a set that also foments discussions around gender identity, drug and alcohol addiction, post-traumatic stress disorder, gun control, xenophobia, immigration and atheism?

This conundrum is also present in the speech of Calderón Kellet, who goes as far as to refute the conventional read of the show as political: "Honestly, we don't think this show is political [...] It really is [about] a Latinx family dealing with right now. [...] We really just talk about things that are happening" (Kellet \& Gomez). In other words, the show is supposedly not political, because it portrays the reality of a Latinx family dealing with now. Her assumption is questionable: what would be the contradiction between a political show and the "reality" of a "Latinx family," "now"? Is not a show that portrays a reality, a minority ethnic background, in the present, inherently political?

We believe the author is not so naive. On the contrary, she is obviously responding to a larger prejudice against "explicitly political" shows-especially comedies. She mitigates the fact that "things that are happening right now" in the middle of Trump's presidency with the Latinx community cannot be taken as anything other than political-even the grapheme $x$ is a nod to a political struggle - by suggesting she is just talking about a regular family, very much based on her own experiences. "Let us bring our guards down to accept one more family show," she seems to be saying. She has to disarm the interlocutor, who wants to label and file the show under the (reductionist?) heading of a "political show." 
What is important here is the very own need to use such stratagem. Lyons and Calderón Kellet are both responding to the presumed notion of a dichotomy between political and non-political subject matter. Between relevant fictionwhich should stay in the realm of "gritty dramas" - and family comedies with universal appeal. In other words, they are situating a well-established tradition of judging relevance and actuality in opposition to the supposedly "universal" in the realm of television comedy. So, let us revisit the particular history of the genre in order to better understand the origin of these assumptions.

\section{An overview of the sitcom history}

\section{Lear and MTM: The domestic sitcom between "relevance" and "character"}

Television scholars agree that something happened in the 1970s, when we witnessed a small revolution in the format of the "classic" 1950s sitcom. Horace Newcomb, in his widely influential study, TV: The Most Popular Art (1974), went so far as creating two different categories: situation comedy and domestic comedy. The first was the more simplistic and formulaic structure of the comedy of errors: a situation that gets out of hand and generates a complication, followed by the widespread confusion of the characters, until everything goes back to normal (resolution). The emphasis would fall on the convoluted plot and on the jokes and physical gags delivered by the performers. I Love Lucy (1951) and The Honeymooners (1952) are the classic examples here.

The domestic comedies of the 1970s, on the other hand, were the product of, among others, Norman Lear, as well as MTM Enterprises, founded by Mary Tyler Moore and her then-husband, Grant Tinker. They represented an evolution over the previous format, as Jane Feuer (34) summarizes:

The MTM and Lear sitcoms, the story goes, took a mechanistic, simplistic framework for one-liners and sight gags and made it into something else: whether an instrument for social commentary (Lear) or a vehicle for character comedy (MTM).

The nomenclature of situation vs. domestic did not really stick outside academic circles: the widespread definition of sitcom remains attached to the format of a 20 to 30-minute show recorded in a studio often before a live audience, with the classic three-camera setup of I Love Lucy. As a matter of fact, almost all sitcoms are situated in a domestic environment-even workplace comedies create a familial dynamic (Feuer 56) - and make plenty use of the "situation, complication, confusion, resolution" structure. However, Newcomb and Feuer correctly realize that the so-called domestic comedies of Lear and MTM subvert the genre by introducing and emphasizing the more complex fictional categories of "social commentary" and "character." In the traditional situation comedy, there 
is "little real development, no exploration of idea or of conflict" (Newcomb 34) while domestic comedies, especially MTM's, would emphasize "persons" over "situations," allowing for "little epiphanies," in which "the situation itself becomes a pretext for the revelation of character" (Feuer 35).

The distinction between the classic (1950s) and the new (1970s) sitcom, therefore, is an analytical tool which helps describing an evolution of the format. The sitcom would never be the same. From now on, stand-alone jokes and lack of depth would be considered inferior: sophisticated audiences watch a sitcom not only for the sake of well-delivered punch lines, but they expect character and plot development in daily doses.

We detect another split. Lear is taken as the representative for the "social commentary" school, while MTM's writers and producers emphasize the priority of "character" above all other fictional categories. All in the Family (1971) and Maude (1972), for instance, were known for tackling current polemic issues, such as the Vietnam War, racism and abortion. The Mary Tyler Moore (1974) and Rhoda (1974), on the other hand, for creating memorable and nuanced characters. Even though both Lear's comedies still make use of developing story arcs for characters, and MTM's shows sprinkle "hot topics" whenever they can, they are still remembered as comparable, but distinct approaches.

Jane Feuer's text quoted above deals extensively with this. What is important for us is realizing the dichotomy is maintained until today. And that instead of representing two valid and equal alternatives, one side has won. Lear's "relevant" sitcoms, up until the late 2010s, seemed a thing of the "political 1970s," while MTM's comedies gave birth to a multitude of "quality" television shows and, more importantly, to the comedy-drama hybrid products of the prime-time drama, such as the influential Lou Grant (1979) and Hill Street Blues (1981). The dominant/hegemonic mode of writing fiction for television is centered around submitting all fictional elements to the primacy of character revelation and depth. "Political" themes or "topical" preoccupations seem like add-ons to lend credibility, distinction or flair. This is why they seem so out of place for comedies, and not for prestige, "gritty" dramas.

Mike Royce, One Day at a Time's co-creator, expresses this perfectly: "Some episodes will deal with more social and political stuff and some episodes will deal with more family stories, but they should all feel like family stories" (Kellet \& Royce). Even though striving for a balance between "social and political stuff" and "family stories," the priority is the latter.

Some critics may find that the show managed to achieve a perfect equilibrium, such as Bradley:

Although a few of these topical elements occasionally play for a beat too long, the series continues to move seamlessly between the modes of comedy and political poignancy; this is, after all, not the first rodeo for Lear or the series' two show-runners, Calderón Kellett and Mike Royce. 
But the division is still marked between "political poignancy" and "comedy." Comedy, as a larger genre, may dare to include these "topical elements" - but as an exception, not a rule. As we have seen in the previous section, Calderón Kellet feels the need to actually defend the show from the implicit accusation of being political—as if it would be a lesser comedy because of that.

\section{The cultural forum ideal}

So far, we have been analyzing the responses of One Day at a Time's critics and creators, who feel the need to emphasize the show's universality as a family comedy against the "accusations" of being political. According to our interpretation, this reveals the hegemonic discourse that condemns overtly political fiction in general, but more specifically in the sitcom.

Another concept that tries to articulate the media's potential for articulating politics and fiction is the concept of "television as a cultural forum," formulated for the first time by Horace Newcomb and Paul Hirsch's homonymous article. This text formulates a somewhat optimistic idea that refutes older formulations of mass culture in general (and television in particular) as a means of mass deception. The authors point out how different ideological positions are present in television content and how this multiplicity contribute to their aesthetic complexity. Just like drama, the novel and other forms of art have been doing for centuries, television would also carry on with a ritualistic function which allows "contemporary cultures" to "examine themselves" (47).

Let us remember that Newcomb and Hirsch (1983) are writing this after a decade of socially conscious programming. Norman Lear's shows gave way to new hybrid products, like $M^{\star} A^{\star} S^{\star} H^{\star}$ (1972), a single-camera comedy that used the setting of the Korean War to discuss the ongoing American campaign in Vietnam. In 1977, the audience could also watch a dramatic miniseries such as Roots, one of the most lauded shows of the United States, which told the story of the American Civil War through the perspective of an enslaved man and his family. That environment certainly helped Newcomb and Hirsch to write about television as being "dense, rich, and complex rather than impoverished" (53).

Both authors saw the medium as way of "raising the questions," without presenting "firm ideological conclusions," a contemporary method for stimulating intelligent (but light and funny) debate between antagonistic points of view. All in the Family is the archetype for this: it depends on the formula of having a divisive issue on the table per week, and witnessing the conflicting family members fight over it. One the one side, Archie Bunker, the conservative working-class provider; on the other, his liberal, college-attending, unemployed son-in-law. The audience can follow not only their rhetorical struggle, but also their character flaws: Archie is often the butt of the joke, but the liberal views of his son-in-law do not prevent him from acting as a lazy and narcissistic college kid.

In a way, "television as a cultural forum" is a framework for understanding all types of cultural content, from journalism to soap operas. The consideration of 
"different points of view" in relation to an issue is also a great motor for creating conflicts and keeping a diverse family audience interested. In an era with few television networks such as the American media landscape of the 1970s, plurality of opinion was a valuable way for a program to reach different demographics at once: every member of the household could see their own points of view "represented" on screen. However, overly political shows like Lear's seemed to wane as television took a turn to "character-centered," MTM-like shows, targeted more and more at specific audience segments, a process which was fueled by the multiplication of specialized cable channels as well.

One Day at a Time returns to the recognized formula of the 1970s: Lear's recipe of dramatizing a small "forum" in a living room. Again, we are presented with a conflict of generations: the old-fashioned, catholic and semi-chauvinist expectations of Lydia, the grandmother, clash with Elena's progressive eco-queer militancy. It is not a show about one or the other, but about the coexistence of both. This is its source of conflict, as well as a great stimulus for getting reacquainted with diverse and often contradictory ideas.

Calderón Kellet's words echo and actualize Newcomb and Hirsch's previous considerations. She states:

I do live in an echo chamber. All of my social media supports what I think and feel, and it was very eye-opening to me because I am a writer. I do want the conversations. I do want those fights. From a writer's perspective, I was upset with myself for not being more educated. Television is the one place where we are allowed to see other people fight with each other and have differences of opinion, and that's the place where I think hearts and minds can be changed (Fernandez, 2016, emphasis added).

After all, what has been called the "filter bubble" (Pariser, 2011) effect of social media is a continuation of the trend to segment markets. Ideological positions find their objects of consumption and their niches in social network and in programming specifically targeted for each demographic's preferences and biases. A show that intends to bring the whole family back together to watch "people fight with each other" over current matters seems to be a welcomed response to this tendency, something recognized by critics of the series as well:

The broadness of this and other progressive multi-cams' humor is probably meant to invite families to watch together, so different generations and political camps can see their viewpoints reflected on the show (Kang, 2017).

The concept of the cultural forum is useful for us to think about these different ambitions and their articulation by the overall format of a show. Having a broader or a narrower target audience may generate more or fewer perspectives within the dramatical scope. Opting for a "family" sitcom instead of a "gritty" drama necessarily implies finding tools to discuss and debate issues in an accessible fashion, taking into consideration the differences of age, gender and class, among 
others. If more points of view have "voices," their characters' multiple vortices of interaction create an environment of gloss and variation, which may add nuance to a healthy debate. Neither of these aspects is fully form nor content, neither chicken nor egg: bringing current topics to the fore may be a conscious decision, but it is also a requirement of producing weekly shows with a fixed cast in need of fuel for conflict.

So this is the potential of the cultural forum ideal. Let us now look at its limits.

\section{Limits to the cultural forum, then and now}

Though optimistic, Newcomb and Hirsh's essay does not shy away from recognizing that the potential for freedom and democratic debate had limits within "American monopoly-capitalism" and "American pluralism" (566). A liberal respect for difference of opinion may question certain values, but can never directly attack the premises of a whole way of life. The very idea of intelligent debate-forum-implies a belief in equal distribution of power, something that can be acted out in regulated roundtables on the television news, or in balanced distribution of time and development of characters in television drama. But has this ideal ever come to an existence outside of the cultural realm?

Todd Gitlin, also writing in the late 1970s and early 1980s, gives us the blueprint for articulating the problems of the cultural forum ideal and the "relevant" fiction of the period by examining the concepts of ideology and hegemony, probably two of the most fruitful tools of Cultural Studies. One of his goals, in "Prime Time Ideology: The Hegemonic Process in Television Entertainment" (1979), is trying to understand exactly how society's contradictions and conflicts were exposed as a crucial part of television content, and yet how these programs end up becoming agents for the reproduction of the status quo. In other words, how could television have a progressive content, yet a regressive function or effect. This matter is expanded in his aforementioned chapter (1983) on the "relevant" fiction of the 1970s. Let us look at some of his arguments.

A great deal of Gitlin's interventions relies on extensive empirical knowledge of the decision-making process in that particular era. His field work involves in-depth interviews with television industry executives and professionals in all the three major networks of American broadcast. Therefore, he notices how "relevant" situation comedies are first and foremost commercial decisions aimed at a liberal, educated elite, in a time when there was demand to see their own social and political preoccupations reflected on screen.

Gitlin circumvents the discussion around the intentions of creators and audiences: any kind of "cultural forum" that allows for the debate of sexism and racism may be produced by people who actually care about these issues, but there are intrinsic limits to the good intentions of individuals. The profit motive thwarts any kind of theme capable of confronting capitalist values; and the fact that the shows are created by and to members of the same liberal elites (either by actual member or by aspirants) restricts their power of insight and 
their drive for change. We may shed light onto some of societies' problems-but what about the things we, in our class positions, do not believe to be problematic? We might advance a cause and examine its pros and cons, but how deep can we see its consequences and its relationship to our own practices? It is not enough to find "contradiction" and "polemic" in television; we should look into who is actually sitting down at the forum, either defining its terms or avidly consuming it as a spectacular product. The concept of ideology here is not a "content" or a "message" to be delivered in propagandistic or subliminal ways, but simply as the limits and conditions intrinsic to context and power.

There is also the problem of the ambiguity of the representations: in domestic comedies, the points of view are so diffuse that different members of the audience can really choose to ignore any kind of progressive message. Gitlin mentions experimental studies about All in the Family finding that "[...] although Archie may have lost the arguments, viewers took away whatever attitudes they brought to the show; racists felt confirmed in their racism, liberals in their broadmindedness and sense of superiority (186)."

The cultural forum was so balanced and the performance of the actors so spectacular that any kind of conclusion to be derived out of logical arguments lost their power. Archie's racism fades in comparison to Caroll O'Connor's trollish charisma. The actor prevails over his character. We can already suggest that something very much alike may be happening to Rita Moreno's praised performance of Lydia in One Day at a Time: the young Isabella Gomez, often her on-screen ideological opponent, hardly stands a chance.

The domestic sitcom also repeats a model of society in which everyone might have slight differences of opinion, but no one is really allowed to leave. In sitcoms, "the family must stay together" is not only a motto of a conservative outlook, but a dramatic imperative of preserving the continuation of the cast for each episode. It takes time to build audience identification - and time is money. Therefore, this dramatic structure, just like our model of liberal democracy, can accommodate some revolt and reform, but it cannot allow for greater disruption. Even the problem of individuality and adherence to a social compact is reproduced: each character has to find certain distinguishing traits-in the case of "relevant" fiction, it helps having a "cause" to fight for-, but these have to somehow adapt and conform to the larger group. This process creates weekly conflicts, but they have to be quickly domesticated; it creates a break, but a partial one (514).

Progressive could mean taking society's conflicts and dramatizing them to their point of maximum tension, showing how they impact the individual and their social relations. However, as Gitlin argues, this kind of content is a preapproved and packaged commodity, going only so far as allowing for weekly doses of entertainment that can pass as reflexive or educational. It can be an exciting trend or not, according to the possibility of profiting for a greater or a lesser demand by a target audience. According to Gitlin, the difference between the 1950s sitcom and the 1970s domestic comedy is simply that the former can completely ignore overtly political (racial, sexual) fissures, whereas the latter has to find ways to include them 
in the plot. It manages to do so with very little harm, thanks to the new fictional conventions of adding more character complexity in the mix.

In other words, "character" (MTM) and "relevance" (Lear) are not incompatible at all. Just like in the interviews by One Day at a Time's creators quoted above, "character" and "family drama" (the domestic sphere, the universal values) are a direct response to the menace of delicate political topics. In these comedies, character arcs, their relationships and the "human" drama involved, domesticate issues, subject them to a secondary, incidental role.

Domestic here also means configuring all dramatic conflicts in terms of "depoliticized forms of deviance, usually ethnic of sexual" (Gitlin 523): the battles between different points of view can develop insofar as they find individual solutions, usually as a change of mind, a new understanding or outlook, "a set of little epiphanies" (Feuer 35) in accordance to other members of the household. Characters may fight about racism and chauvinism, for instance, but at the end of each arc they will have to make individual compromises until the source of conflict is neutralized. By the end of the episode, the arguments cannot have broken the family, nor can they have led to disruptive political struggle.

If the shows of the 1970s included more and more diverse ethnic and/ or sexual minorities, Gitlin questioned how these groups were actually in opposition to hegemonic values. The Mary Tyler Moore Show centered on a single, professional woman, who in that time could be seen as an emergent political actor in opposition to the traditional housewife. The problem is: in the middle of a deep economic crisis, when fewer households were affording to have just one (male) provider, exalting the "professional woman" was not, in any way, adverse to the economic system. Much on the contrary, it contributed to a new ideal work ethic for a part of the labor force that had not been required to go out into the world and make money. In other words, it represented a moment where questioning traditional gender roles was not a menace to the functioning of society as whole, it was actually desirable. For Gitlin, this is the difference between a truly progressive stance and what we see in relevant sitcoms. They may incorporate themes and ideals which appear to advance important causes. However, in reality, these causes have already become instrumental to the status quo.

Lastly, Gitlin's text has the merit of asking scholars to bring "the discussion of cultural hegemony down to earth" (509). He asks:

How do the formal devices of TV prime-time programs encourage viewers to experience themselves as anti-political, privately accumulating individuals? And how do these forms express social conflict, containing and diverting the images of contrary social possibilities?

That means examining how ideology operates in actual works, and in finding methodological tools for the job. This is what we will do in the next section, where we present an analysis of the actual television text of One Day at a Time to show exactly the domestication of the cultural forum taking place. 


\section{Elena's quinceañera: a hierarchy of values}

One Day at a Time's first episode sets up a conflict somewhat typical of a Lear-type situation comedy. Elena is about to turn fifteen and according to the Cuban tradition is expected to have a quinceañera. However, since her character is presented as the stereotypical militant youth, with strong convictions in matters of gender equality, she refuses to have the party, claiming it reinforces an outdated expression of sexist, patriarchal values.

Just like in All in the Family, the show puts forward the classic conflict of generations by setting the battlefield for two different ideological positions: the liberal perspective of a young feminist, and the conservative expectations of her mother, Penelope, and Lydia. The explicit issue is the inherent sexist nature of a quinceañera, but there is also an underlying tension between a more individualistic ethical stance and the respect for cultural customs. The family is willing to ignore the undertones of the quinceañera to preserve the traditional gathering, while Elena is ready to throw her heritage out of the window because it contradicts her personal beliefs.

Both layers express structural conflicts and paradoxes. They articulate a challenge in embracing cultural customs whilst recognizing their "uglier" aspects. And they set up the inner conflict in Elena's character: she may feel like the righteous social justice warrior, but her behavior also alienates her from her cultural origins and family. Throughout the series, Elena's conflict is further complicated by her coming out as a lesbian and by her constant feelings of inadequacy: she does not speak Spanish as fluently as her brother and she can "pass" as white. These are extremely complex problems, but a sitcom should be able to solve each of them in 30 minutes.

At the end of the first episode, Penelope sits down with her daughter and explains why she wants the quinceañera: it is not about blindly following a tradition, but about showing off to all their relatives; about proving that Penelope, after her divorce, is still a good mother. Thus, the political issue is turned secondary by an individual one: playing the debutante is no longer about conforming to the patriarchy, but about helping her mother regain her self-esteem. Elena compromises, she will have the quinceañera because she understands that, inside, she is still a feminist-even though she does not need to do anything radical about it. She can be a good daughter and still feel like a progressive militant.

Let us remember that this is a formal imperative. Conflicts can lead to complications that will entertain us for a while: how will Elena tell her family about her desires? Can she hide them? Who will find out first? How will they react? The suspense presents opportunities for jokes and gags. But, in the end, nothing can truly endanger the unity of the family/ensemble. And form becomes ideology: by means of the constant repetition of similar schemes, all relevant debates are subsumed under the category of individual decisions and negotiations, which ultimately lead to some kind of compromise and understanding. In other words, she behaves according to a hierarchy of values: 
the individual needs of members of my family are more important than any overtly political/disruptive action.

There is a real, dangerous tension lurking behind Elena's conflict: the liberal values of women's autonomy are in direct contradiction to the traditional female role in a quinceañera. To accept and embrace "white" liberal values often means to resist deeply embedded cultural customs, to not take part in them. However, in a series that tries to balance matters of identity and a progressive political agenda, this is easier said than done. To actually point the finger at an ancient tradition and denounce its embedded sexism to the point of disruption can only go so far as to pose questions, make speeches and pretend revolt it, but in the end go through with it anyway. So, the regular procedure is to sweep the problem under the mat: it is enough to verbally acknowledge the sexist undertones of a tradition, to discuss it and criticize it—but that does not mean the party has to be cancelled. Furthermore, it emphasizes Elena's militancy as a "quirk" of her character. She can be a rebel, without actually having to do anything actually revolutionary. It is more important that Elena, as an individual character, solves her own problems of inadequacy in relation to the expectations of her family than to have her acting out her beliefs in direct opposition to them.

The same procedure takes place with Lydia, Elena's grandmother. As a member of an older generation and a fervent Christian, the whole family is apprehensive about her reaction upon hearing of Elena's recently discovered sexual orientation. But Lydia, in the name of the family's cohesion, gracefully accepts Elena without hesitation, and even sews her a suit instead of a dress for the quinceañera. Again, this is a compromise that neutralizes any really dangerous conflict: different generations, with different religious beliefs and sexual orientations, can be a part of the same household. Even if the tradition represents the submission of women, that is okay, because Elena is wearing something slightly more progressive. Thus, we get to keep the superficial aspects of a cultural custom, the quinceañera as a festive, exotic Latino party, while the deeply embedded underlying sexual/ political tone is something you can ignore or overlook after a few ruses.

Elena's father offers the counterproof: upon realizing his daughter is a lesbian, he cannot leave his convictions aside, and so he abandons her during the ceremony. The character cannot respect the hierarchy of values, he cannot put the family first. He acts according to his beliefs, which come from both religion and from the machismo of his Latino upbringing. And that is the real taboo in a domestic comedy. Of course, it is also an opportunity for dramatic development of character: the second season will show the father's individual struggle overcoming his prejudices and finding back his place in the family.

Newcomb and Hirsch realized that domestic comedies and television fiction in general needed to "work out" solutions to the fault lines of society (52). Gitlin criticized the "easy solutions": "however deeply the problem is located within society, it will be solved among a few persons: the heroes must attain a solution that leaves the rest of society untouched" (524). Here we are exposing one mechanism that allows for solutions to be found so easily: you put 
family first, always, and you convert social problems into individual struggles. It is a simple hierarchy.

Elena's conflict is exemplar. Other characters and situations reinforce our argument. For instance, the series depict the character of Schneider, the owner of the building where the Alvarez family lives. Structurally, their landlord-tenement relationship is based in a conflict of interest: the size of his profit is proportional to how much he is willing to go into the family's pocket. Potentially, he could be a villain: the evil landlord who arbitrarily raises the rent or threatens them with eviction, as a cruel reminder of money's cold rule outside the security of the domestic living-room. However, this is neutralized from the start: Schneider is portrayed as a part of the family, a replacement (but non-sexualized) figure for the lost father, and also a kind of adopted son, since his own parents abound with money, not warmth. The schematism is transparent: the love he could not receive from wealthy parents is given "for free" from a struggling Latino family. His attachment to the Alvarez, while not consanguineous, is his number one priority - and we can completely forget he is the landlord. Ironically, his parasitic relationship is actually amplified, as he profits from both the property (without ever having worked for it) and from the love and care a typical Latino family should have in abundance. In this way, the show avoids tackling the class fracture directly. Why do some people get to inherit money and profit without doing any work? Why struggling families can never save enough to have their own houses? These questions do not have the opportunity to arise, because all we see is Schneider, the character, suffering because of his privilege (and not despite of it).

\section{Conclusion}

John Hartley, also a believer in the cultural forum ideal, proposed that television advances a new form of citizenship, a "cultural or do-it-yourself" (1999, 154) citizenship. The idea is that, in a postmodern world, identities cannot be attached to "political differences based on territory, ethnicity, law and heritage" (158). The television audience, by choosing what to watch, could supposedly mix and match whatever parts they want to incorporate into their sense of self. We are arguing that domestic comedies are dramatical equivalents of this ideal: Elena's DIY party and her suit are also a collage $e^{5}$ of things she wants to underscore about herself, leaving out the undesirable parts. She can be a good Latina daughter, performing Latino traditions, but also a militant feminist. Schneider can come from a whole different class, race and ethnic background, but he can choose to identify with this peculiar family, to the point of speaking Spanish more fluently than Elena. Lydia can be an 80-year old fervent-catholic matriarch, but also jump up and down like a young dancer and fully embrace her lesbian granddaughter.

We are not arguing that these kinds of alliances are impossible (or even infrequent) on a personal level. People can certainly find ways to accommodate and to incorporate multiple aspects from various sources into their own sense of identity. We do, however, need to emphasize that the very form of these relevant 
domestic comedies encourages the gloss over fundamental and contradictory differences. They emphasize the (often easy) solutions to the detriment of the tensions and contradictions, resulting in the idea that no choices are irreversible: Elena can have both her liberal feminism militancy and her patriarchal cultural party; Schneider can be landlord and adoptive son; Lydia can play the old conservative and the flexible, accepting flirt. As long as they stay close to the family, nothing can get in the way. Unsolvable differences, irreducible conflicts of interest are put out of the frame.

This is the actual limit of the cultural forum ideal, the democratic notion of a reasonable argument among individual peers. What must be preserved is not any particular interest, but the conditions and the environment of the debate itself. That is why all sources of conflict in a domestic comedy are threats to the stability of the family-and the whole family must intervene, just like in a UN security council. As Jane Feuer argues, any single problem between a couple raises fears of divorce and disruption (38). The worst that can happen is the breaking apart of the environment itself.

Political topics, in Lear-like sitcoms, when they enter the realm of representation, threaten the stability of the liberal debate. In real life, when different groups and individuals realize their interests might clash, political solutions are necessary to allow for its resolution. However, as we noted in the first part of our discussion, politics in the cultural sphere is taken as a petty, secondary concern. Writers and producers bring issues in vogue, but rapidly make them submit to the requirements of the family character drama.

\section{Notes}

1. Hannah Stewart's work (2019) investigates this topic in depth, and we highly recommend this reading.

2. We thank the suggestion of one anonymous reviewer from Ilha do Desterro for calling our attention to this classic reference. Shohat's and Stam's view are now so widespread in the academia that in the first draft of this article we did not realize how similar our approaches were. The chapter mentioned here certainly offers a thorough introduction to the problems of the "stereotype" critique.

3. Castañeda (2020, p. 473), who is very optimistic about digital TV's potential to foster counter-narratives, stresses that technologies are not neutral apparatuses, therefore, the negative representation of Latinx community on broadcast television is strictly linked to a colonial history of racial hegemony translated into the exploitation of Latino communities. According to the author, the financial and structural difficulties Latino/Latina creative professionals face in entering the Television industry are significative obstacles in the pursuit of complex Latinx representation on TV.

4. We thank an anonymous reviewer from Ilha do Desterro for this reference.

5. Newcomb and Hirsch's text also uses the term "bricoleur" to refer to the television audience: "we begin to think of the television viewer as a bricoleur who matches the creator in the making of meanings" (52). 


\section{References}

Alvarez, Lauren. "Was Netflix Justified in Cancelling 'One Day at a Time'?” Forbes, 14 Mar. 2019, https://www.forbes.com/sites/laurenalvarez/2019/03/14/did-netflixever-really-care-about-one-day-at-a-time/.

Bochco, Steven, and Michael Kozoll. Hill Street Blues, NBC, 1981.

Bradley, Laura. "How One Day at a Time Captures a Community Most TV Ignores." Vanity Fair, 26 Jan. 2018, https://www.vanityfair.com/hollywood/2018/01/oneday-at-a-time-season-2-review-interview-rita-moreno-justina-machado-gloriacalderon-kellett.

Brooks, James L., et al. Lou Grant, CBS, 1977.

Brooks, James L., and Allan Burns. The Mary Tyler Moore Show, CBS, 1970. Rhoda, CBS, 1974.

Castañeda, Mari. "Television and Its Impact on Latinx Communities." The Oxford Handbook of Latino Studies, edited by Ilan Stavans, Oxford University Press, 2020, pp. $462-484$.

Curtin, Michael. "On Edge: Culture Industries in the Neo-Network Era." Making and Selling Culture, edited by Richard Ohmann, Wesleyan University Press, 1996.

Czajkowski, Elisa. "How Old-School Sitcoms Made Their Triumphant Return." The Guardian, 18 Jan. 2017, https://www.huffpostbrasil.com/entry/one-day-at-atime-canceled-netflix_n_5cb4e23ee4b098b9a2d870cf?ri18n=true.

D’Ávila, Arlene. Latinos, Inc.: The Marketing and Making of a People. University of California Press, 2001.

del Río, Esteban, and Kristin C. Moran. "Remaking Television: One Day at a Time’s Digital Delivery and Latina/o Cultural Specificity." Journal of Communication Inquiry, vol. 44, no. 1, Jan. 2020, pp. 5-25, doi:10.1177/0196859918825332.

Fernandez, Maria Elena. "After Two Decades Away, Norman Lear Has a New TV Show." Vulture, Dec. 2016, https://www.vulture.com/2016/12/norman-lear-oneday-at-a-time-c-v-r.html.

Feuer, Jane. “The MTM Style." MTM: “Quality Television,” edited by Jane Feuer et al., British Film Institute, 1984.

Fiske, John, and John Hartley. Reading Television. 1978. Routledge, 2003.

Gelbart, Larry, and Gene Reynolds. $M^{\star} A^{\star} S^{\star} H$, CBS, 1972.

Gitlin, Todd. "Prime Time Ideology: The Hegemonic Process in Television Entertainment." Social Problems, vol. 26, no. 3, 1979.

“The Turn Toward 'Relevance." Inside Prime Time, Pantheon Books, 1983.

Gleason, Jackie. The Honeymooners, CBS, 1955.

Hartley, John. Uses of Television. Routledge, 1999.

Kang, Inkoo. "One Too Many Issues At A Time." MTV News, 1 Oct. 2017, http:// www.mtv.com/news/2970578/one-too-many-issues-at-a-time/.

Kellet, Gloria Calderón. "Meet the Woman Who Gave 'One Day At A Time' Its Bicultural, Latino Flavor. Interview by Ana Sofía Peláez." NBC News, 26 Jan. 2017, https://www.nbcnews.com/news/latino/meet-woman-who-gave-one-day-timeits-bicultural-latino-n711476.

Kellet, Gloria Calderón, and Isabella Gomez. “I’m Making White-Man Money Now': A Conversation with 'One Day at a Time' Executive Producer Gloria Calderón Kellett and Actress Isabella Gomez. Interview by Zack Stanton.” Political, 1 Jan. 
2020, https://www.politico.com/news/2020/01/01/one-day-at-a-time-interviewwomen-rule-091484.

Kellet, Gloria Calderón, and Mike Royce. "'One Day at a Time' Bosses on Politics, Production Postponement and Weekly Format of Season 4. Interview by Danielle Turchiano." Variety, 20 Mar. 2020, https:/variety.com/2020/tv/features/ one-day-at-a-time-season-4-alex-girlfriend-female-sexuality-census-politicsinterview-1203535743/.

One Day at a Time, Netflix and Pop, 2017.

Lear, Norman. All in the Family, CBS, 1971.

. One Day at a Time, CBS, 1975.

Lear, Norman, and Bud Yorkin. Maude, CBS, 1972.

Lepore, Jill. These Truths: A History of the United States. W. W. Norton, 2018.

Loofbourow, Lili. “One Day at a Time's Cancellation Didn’t Surprise Me. The Uproar Over It Did.” Slate, 18 Mar. 2019, https://slate.com/culture/2019/03/one-day-at-atime-cancellation-backlash-netflix.html.

Lotz, Amanda. The Television Will Be Revolutionized. New York University Press, 2014.

Lyons, Margaret. "Review: The Euphoria of 'One Day at a Time."' The New York Times, 25 Jan. 2018, https://www.nytimes.com/2018/01/25/arts/television/one-day-at-atime-netflix-review.html.

Mastro, Dana E., et al. "Exposure to Television Portrayals of Latinos: The Implications of Aversive Racism and Social Identity Theory." Human Communication Research, vol. 34, no. 1, Wiley-Blackwell Publishing Ltd., 2008, pp. 1-27, doi:10.1111/j.14682958.2007.00311.x.

Mastro, Dana E., and Elizabeth Behm-Morawitz. "Latino Representation on Primetime Television." Journalism \& Mass Communication Quarterly, vol. 82, no. 1, SAGE Publications, June 2016, pp. 110-130, doi:10.1177/107769900508200108.

Newcomb, Horace. TV: The Most Popular Art. Anchor P, 1974.

Newcomb, Horace, and Paul Hirsch. "Television as a Cultural Forum: Implications for Research." Quarterly Review of Film Studies, vol. 8, no. 2, 1983, pp. 43-55, doi:10.1080/10509208309361170.

Oppenheimer, Jess, et al. I Love Lucy, CBS, 1951.

Pariser, Eli. The Filter Bubble: What the Internet Is Hiding from You. Penguin Press, 2011.

Piñero, Julie. “'One Day At A Time’ And The Future Of Latinx TV." HuffPost US, 14 Apr. 2019, https://www.huffpostbrasil.com/entry/one-day-at-a-time-canceled-ne tflix_n_5cb4e23ee4b098b9a2d870cf?ri18n=true.

Sepinwall, Alan. "Netflix's ‘One Day At A Time’ Remake Gives 2017 TV A Timely, Funny, Poignant Start." Uproxx, 4 Jan. 2017, https://uproxx.com/sepinwall/oneday-at-a-time-netflix-review/.

Shohat, Ella, and Robert Stam. "Stereotype, Realism and the Struggle over Representation." Unthinking Eurocentrism: Multiculturalism and the Media, Routledge, 1994.

Stevenson, Alysia. "Netflix's ‘One Day at a Time’ Needs to Rethink How They Portray Elena ASAP." Femestella, 28 Feb. 2019, https://www.femestella.com/one-day-attime-review-season-3/. 
Stewart, Hannah. Investigating Latino Stereotypes and Identification in One Day at a Time: A Rhetorical Criticism of Latino Representations in Entertainment Media. University of Colorado Boulder, 2019, https://scholar.colorado.edu/concern/ undergraduate_honors_theses/c821gk20p.

Recebido em: 09/07/2020

Aceito em: 20/11/2020 